\title{
Disrupting the public-private distinction: excavating the government of carbon markets post-Copenhagen
}

\author{
Eva Lövbrand and Johannes Stripple
}

\section{Linköping University Post Print}

N.B.: When citing this work, cite the original article.

The definitive peer-reviewed and edited version of this article is published in:

Eva Lövbrand and Johannes Stripple, Disrupting the public-private distinction: excavating the government of carbon markets post-Copenhagen, 2012, Environment and Planning. C, Government and Policy, (30), 4, 658-674.

http://dx.doi.org/10.1068/c11137

Copyright: Pion http://www.pion.co.uk/

Postprint available at: Linköping University Electronic Press http://urn.kb.se/resolve?urn=urn:nbn:se:liu:diva-84364 


\section{COVER SHEET}

\section{Disrupting the public-private distinction: excavating the government of carbon markets post Copenhagen}

Authors: Eva Lövbrand (1) and Johannes Stripple (2)

(1) Centre for Climate Science and Policy Research, Linköping University, 60147 Norrköping, Sweden. Email: eva.lovbrand@ @iu.se

(2) Department of Political Science, Lund University, Box 52, 22100 Lund, Sweden. Email: Johannes.stripple@ svet.lu.se

Accepted for publication in Environment and Planning $C$

\section{Acknowledgements:}

The study has been made possible through financial support from BECC, the Swedish government's strategic focus on climate change hosted by the Faculty of Science at Lund University, the Low-Carbon Energy and Transport Systems (LETS) project, financed by the Swedish Environmental Protection Agency (among others), and the Linköping University LiU FoAss programme, and the Swedish Environmental Protection Agency is greatly appreciated.

Length: 9600 (excl cover sheet and abstract) 


\begin{abstract}
This paper draws upon the recent carbon market turmoil to understand how the private realm is imagined in global climate governance. Instead of asking which entities (e.g. public or private authorities) that govern the carbon economy, we draw attention to the procedures (e.g. caps on emissions, techniques of verification or performance standards) by which carbon markets are made thinkable and governable as administrative domains. When focusing on these 'calculative practices' carbon market governance does not signify a retreat of the state. Rather, in this paper we argue that the involvement of non-state actors in the governance of carbon markets represents a transformation of political rule that replaces formal and hierarchical techniques of government with more indirect regimes of calculation. From this vantage point, carbon market governance emerges as an expression of a changing rationality of government where the private realm becomes elevated from being a passive terrain to be acted upon and instead turned into an entity that is both object and subject of government.
\end{abstract}




\section{Introduction}

Since the entry into force of the Kyoto Protocol and the inception of the EU Emissions Trading Scheme (EU ETS) in 2005, as well as the more recent emergence of regional carbon markets in North America and New Zealand, global transactions in emission reductions have become more than mere social imagining. As estimated by the World Bank (Kossoy and Ambrosi, 2010), as much as 8700 million tonnes of carbon dioxide equivalents ( $\mathrm{tCO} 2 \mathrm{e})$ were traded by public and private actors in the year 2009 to a total value of 143735 million USD. At the same time the past years have been challenging for carbon markets. The global economic crisis, which started in late 2008 and intensified in 2009, reduced the demand for carbon assets and directed financial institutions away from risky carbon investments. The EU ETS, the flagship of the European Union's climate change policy, was in 2009 marked by controversy as a result of tax-fraud charges and allegations of double accounting of carbon offset credits (Kossoy and Ambrosi, 2010). Due to the regulatory uncertainty produced by the failed $15^{\text {th }}$ Conference of the Parties (COP 15) to the UN Framework Convention on Climate Change (UNFCCC) in Copenhagen in December 2009, the value of the primary Clean Development Mechanism (CDM) market also fell by double digits in 2010 for the third year in a row, ending lower than it was in 2005 (Linacre et al., 2011).

In this paper we draw upon this carbon market turmoil to understand how the private realm is imagined in global climate governance. In particular we ask to what extent recent developments in the carbon economy prompt us to rethink the ways in which the climate is governed in the post-Copenhagen era. For scholars of global governance, the worldwide creation of carbon markets is often taken to exemplify a broader turn in environmental policy making towards market liberalism, flexibility and pluralism, where the governance of emission credits involves 'agency beyond the state' at different political levels and across various jurisdictions (Pattberg and Stripple, 2008; Bernstein et al., 2010). Hence, the rise of carbon markets is typically conceptualised along the public-private continuum. In this paper, by contrast, we do not ask which entities (e.g. public or private authorities) that govern the carbon economy. Drawing upon Foucauldian governmentality studies (Miller and Rose, 2008; Neumann and 
Sending, 2010), we are instead interested in the procedures by which carbon markets are made thinkable and operational as administrative domains. When focusing on these "calculative practices" (Miller and Rose, 2008: 11), carbon market governance does not signify a retreat of the state or politics as often implied by students of private governance (e.g. Strange, 1996). Rather, in line with Neumann and Sending (2010), we argue that the carbon economy is as an example of a changing rationality of government where the private realm becomes elevated from being a passive terrain to be acted upon and turned into an entity that is both object and subject of government.

We begin our analysis by outlining what a Foucauldian understanding of government does to the concept of governance and the public-private distinction. We here approach "the retreat of the state" as a neo-liberal technique of government that imagines non-state actors as active partners in the making and implementation of climate policy. In the second section we outline the ways of thinking necessary to approach one tonne of avoided or sequestered carbon dioxide emissions as a tangible and tradable commodity, and offer a brief overview of contemporary carbon markets where this new commodity is produced and transformed into different carbon currencies. We move on to compare two concrete offset contracts and one carbon allowance, bought by the authors of this paper to compensate for air travels in 2007 and 2011 . We trace the accounting techniques, standards and auditing schemes that have brought these contracts into being and made them available for sale in the online web stores of carbon brokers such as Tricorona, Climate Care and the Swedish Society for Nature Protection. Finally, we discuss what those messy sets of rules, practices, norms and authority relations tell us about the public-private distinction in post-Copenhagen climate politics. In a time when carbon market governance is questioned, do we need to reconsider how the private realm and non-state actors are mobilised in the name of climate protection?

\section{From governance to governmentality}

Since the 1990s when global governance emerged as a new and powerful research agenda, scholars have sought to understand the changing role of the state in a time of globalisation (Rosenau and Czempiel, 1992). By drawing attention to the rise of hybrid, non-hierarchical and network-like modes of governing on the global stage, this 
literature has suggested that the state is no longer the sole, or even the principal, source of authority in the international system. As non-state actors have taken on an increasing number of governance functions, the sources of - and institutional locus for - authority have changed (Cutler et al., 1999; Hall and Biersteker, 2002). In the study of global climate governance, an increasing number of scholars have analysed this trend by mapping climate governance arrangements according to the types of actors and sources of authority involved. Most studies have identified a continuum of governance arrangements from those that only involve public actors, to hybrid arrangements established in collaboration between public and private actors, and finally purely private governance arrangements (see Bäckstrand, 2008; Pattberg and Stripple, 2008; Andonova et al., 2009).

The carbon economy is often used as a case in point in these studies. As argued by Bernstein et al. (2010: 164), "carbon markets have become a dominant feature of global climate governance, both within and outside the multilateral treaty process, raising questions about the changing nature of power and authority in global environmental governance." It is an arena where a wide array of non-state actors such as project developers, investors, carbon brokers, consultancy firms and third party auditors have assumed a range of governance functions in parallel to, and oftentimes beyond, the state (see Newell and Paterson, 2010; Stripple and Pattberg, 2010). This blurring of public and private boundaries has gained considerable scholarly attention and has raised questions about the fragmentation of the climate governance order and the capacity of the state and public regulation in the post-Kyoto era (Biermann et al., 2009; Bernstein et al., 2010). It has also prompted questions about effectiveness and legitimacy (Bäckstrand, 2008; Lövbrand et al., 2009; Biermann and Gupta, 2011). Do carbon markets represent an effective response to the climate threat? What are the implications for accountability, transparency, representation and burden sharing?

While this paper shares governance scholars' interest in the carbon economy, it raises a different set of questions. Instead of asking who has power and authority in climate governance, we are interested in the processes by which carbon markets are made thinkable and operational in the first place. Inspired by Foucauldian governmentality studies (Neumann and Sending, 2010; Miller and Rose, 2008; Barry et al., 1996), we 
focus on what Dean (2004: 2, emphasis added) calls "the how of governing"; i.e. question of what processes enable or constrain agency. By moving from who to how questions, we are able to take a step back and analyse the constituting ways of thinking and acting that make up the carbon economy and render it practicable and amendable to intervention (cf. Miller and Rose, 2008). This analytical approach has recently gained ground in the study of carbon markets (see, for instance, Oels, 2005; Lövbrand and Stripple, 2010; Lovell and Livermann, 2010) ${ }^{1}$, and resonates with the work of market sociologists and actor-network theorists. Drawing upon what Callon (1998: 2) has called "the performativity of economics", a growing scholarship has examined how economic theory and the every-day practices and products of financial actors perform or constitute the carbon economy (MacKenzie and Millo, 2003; Knox-Hayes, 2009; Descheneau and Paterson, 2011; Bumpus, 2011).

According to market sociologists, this performativity is not confined to words but also includes the many practical methods, calculation tools, datasets and technical instruments used to stabilise carbon market transactions (Muniesa et al., 2007: 4-5, McKenzie et al., 2007). A Foucauldian analytics of government shares this interest in the practical dimensions of governing. It is an analytical approach that examines the conditions under which "regimes of practices" come into being, are maintained and transformed (Dean, 1994: 21). However, governmentality studies also seek to understand the particular forms of knowledge and rationalities that these practices give rise to, and depend upon, and characteristic ways of seeing, knowing and forming subjects, selves and agents (ibid). As explained by Miller and Rose (2008: 15), Foucauldian analytics of government assume there are intrinsic links between ways of representing and knowing a phenomenon, on the one hand, and ways of acting upon it as to transform it, on the other. "Thus to analyse mentalities of government is to analyse thought made practical and technical" (Dean, 1994: 18). Following this analytical tradition,

\footnotetext{
${ }^{1}$ But also elsewhere in wider post-structural accounts of the rationalities and practices by which a carbon-constrained world is represented, categorised and ordered. Presentations at a recent workshop in Lund (Stripple et al 2011) covered a range of sites (e.g. the body, the home, the shopping centre, the firm, the city, the forests, international bureaucracies, financial flows, scenario making, migrants and refugees) where rationalities and subjectivities around climate change and carbon are formed and contested.
} 
this paper both explores the practical techniques that make up the carbon economy, and the systematic ways of thinking that these techniques give rise to and rest upon.

In the field of governmentality studies, extensive attention has been devoted to neoliberalism as governmental rationality (Dean, 1994; Barry et al., 1996; Miller and Rose, 2008; Neumann and Sending, 2010). As summarised by Nicolas Rose (1996: 41 , neo-liberal or advanced liberal rule seeks to "degovernmentalize the State, to destatize the government, to detach the substantive authority of expertise from the apparatuses of political rule, relocating experts within a market governed by the rationalities of competition, accountability and consumer demand." It is a system of thought that sets out to govern "through the regulated choices of individual citizens, now construed as subjects of choices and aspirations to self-actualization and self-fulfilment" (Rose, 1996: 41). To that end neo-liberal strategies of government are dependent upon techniques (e.g. schooling, health promotion campaigns) that promise to create responsible individuals who are encouraged, freely and rationally, to govern themselves. Dean (1994) has distinguished such "technologies of agency" from "technologies of performance". Whereas the former seek to engage individuals as active and free citizens, as informed and responsible consumers, and as agents capable of taking control of their own risks, the latter establish norms, standards and quality criteria against which performance is monitored, measured and optimised (Dean, 1994: 168-169). Hence, neo-liberal rule both presupposes the existence of free subjects of desire and choice, while, at the same time, shaping, moulding and governing that freedom "at a distance."

In the following sections of this paper we draw upon this literature to characterise the constituting ways of thinking and acting that make up the carbon economy and render it practical to intervention. In particular focus are the "technologies of performance" produced by the complex network of relations, organisations and apparatuses in the carbon marketplace. When focusing on these calculative practices, we do not have to account for government in terms of "the power of the State" (Miller and Rose, 2008:56). Neither do we have to interpret the ascendancy of non-state actors in shaping and carrying out global governance functions as a shift in authority from the public to the private realm (Neumann and Sending, 2010). Rather, the rise of carbon off- 
setting technologies emerges as an expression of a neoliberal governmentality that imagines the market as an active and responsible partner in the governance of climate change.

\section{Making up the carbon economy}

The carbon economy is a young phenomenon. Less than a decade ago, observers questioned the possibility of an international trade in carbon credits. As argued by Victor and House (2004), the creation of a new global currency requires institutional coordination that is unprecedented in the history of international environmental law. While these institutional concerns have prevailed in some academic circles (e.g. Wara 2007; Prins and Rayner, 2007), carbon trading is today an established practice. In 2009 the global carbon trade amounted to 8700 million tonnes of carbon dioxide equivalents to a total value of 143735 million USD (Kossoy and Ambrosi, 2010). Modelled on the global financial market, the carbon economy has mimicked existing market products and processes (Knox-Hayes, 2009). Hence, it is today commonplace to talk about primary and secondary carbon products (e.g. futures, swaps and options), as well as different carbon currencies (e.g. European Union Allowances/EUAs, Certified Emission Reductions/CERs, Verified Emission Reductions, VERs). While these products and currencies are traded at different cost and in different market segments, they all refer to the same commodity; one tonne of carbon dioxide equivalents in the atmosphere $(1 \mathrm{tCO} 2 \mathrm{e})$.

The invention of the " $\mathrm{tCO}_{2} \mathrm{e}$ " as the basic unit of account dates back to COP 7 in Marrakesh in 2001, and is inscribed in the resulting Marrakesh Accords (FCCC, 2001: 8; See also Paterson and Stripple, 2011 forthcoming). Since then this fictional single unit has been adopted in almost all carbon markets, and is today necessary for the carbon economy to function. Currently, there are two market procedures, or systems, by which the "tCO2e" is transformed into a tangible good: first, cap and trade systems; and second, baseline and credit systems. A cap and trade market is created when a collective of emitters within a certain jurisdiction receives a cap on their emissions. Within that cap, emitters are allowed to trade the allowances among each other. In a baseline and credit market, on the other hand, the carbon credits are equal to the difference between emissions after mitigation measures vis-à-vis a baseline (i.e. the 
emission trajectory under a business as usual scenario). The cap and the baseline, respectively, are consequently essential in the making of the "tCO2e" into a tradable good. We can further distinguish between compliance markets, which result from public regulation (e.g. the Kyoto Protocol or national emission trading schemes), and voluntary markets, which do not rely on public regulation to generate demand. Compliance markets as well as voluntary markets can be designed as cap and trade systems or as baseline and credit systems. These distinctions result in the following typology (see Table 1).

Table 1. Compliance and voluntary carbon markets. Adapted from Stripple and Lövbrand (2009)

\begin{tabular}{|c|c|c|}
\hline Carbon markets & Compliance market & Voluntary market \\
\hline Cap and trade & $\begin{array}{l}\text { Kyoto Emissions Trading (IET), } \\
\text { EU ETS, } \\
\text { New Zealand ETS, } \\
\text { Regional Greenhouse Gas Initiative } \\
\text { (RGGI), } \\
\text { California Climate Registry (CCAR), } \\
\text { Personal Carbon Allowances (PCA), } \\
\text { Tradable Energy Quotas (TEQ), } \\
\text { Cap and Share (C\&S) }\end{array}$ & $\begin{array}{l}\text { Japanese Voluntary ETS } \\
\text { Sector No-Lose Targets } \\
\text { (SNLTs) } \\
\text { Carbon Reduction Action } \\
\text { Groups (CRAGs) }\end{array}$ \\
\hline $\begin{array}{l}\text { Baseline and } \\
\text { credit }\end{array}$ & $\begin{array}{l}\text { Clean Development Mechanism } \\
(\mathrm{CDM}), \\
\text { Joint Implementation (JI) }\end{array}$ & $\begin{array}{l}\text { Voluntary Carbon Offset- } \\
\text { ting }\end{array}$ \\
\hline
\end{tabular}

Central to all carbon markets represented in Table 1 is the idea that reductions of greenhouse gas emissions have the same atmospheric effect wherever they are carried out. Although the activities underpinning the reduced emissions may involve different people under very different circumstances, climate science tells us that a tonne of carbon dioxide equivalents is the same regardless of its location on Earth. While this imagining of an atmospheric mixing of carbon can be traced back to a long series of developments within meteorology and biogeochemistry during the past 100 years, and is 
closely linked to the history of climate science (for an overview, see Weart, 2003), the idea to trade emission reductions was born out of the resource economics literature and thinkers such as Pigou in the 1920s, and later Dales (1968) and Coase (1960). As Callon (2009: 538) puts it, "without this contribution from economic theory, carbon markets would have been literally unthinkable". Coase (1960:44) argued that if polluters were given the right to pollute, and to settle the level of compensation for sufferers through the market, a social optimum level of pollution would arise. Provided that the market is fully competitive, such private bargaining will offer a more efficient pollution control than government regulation. While Coase based his theory on examples from local resource and pollution controversies in the UK and USA, carbon markets have extended the theory's geographical reach. Since the marginal costs of reducing greenhouse gas emissions differ within industries and among countries, emissions trading is today imagined as the way to reach a given reduction target at lowest total cost (see, for instance, Stern, 2006; Eliasch, 2007).

Resting upon this mix of ideas from climate science and resource economics, the carbon economy has turned into an interesting creature. According the Descheneau and Paterson (2011) the carbon economy, and its associated and interconnected markets, is, on the one hand, driven by a sense of passion for the climate. Designed to mitigate human-induced climate change, the trade in carbon seeks to mobilise knowledgeable and responsible consumers and purchasing firms who assume control over their greenhouse gas emissions and 'do good' through the carbon market place (Lovell et al. 2009; Paterson and Stripple, 2010). Through a wide set of "technologies of agency" such as carbon calculators, footprints, budgets and allowances, individual consumers and corporations are "responsibilized" and asked to assume moral duties that were once assigned to governments (Shamir, 2008). While this "tapping of passion for climate change" (Deschenau and Paterson, 2010: 7) may be most pronounced in the baseline-and-credit markets, also cap-and-trade systems such as the EU ETS seek to embed social concerns in the market and hereby mobilise corporate actors as economic-rational subjects with moral agency.

On the other hand, the carbon economy is also about routine practice (Descheneau and Paterson, 2011). Drawing upon the expertise and social connectivity of the finan- 
cial service centres in London and New York, carbon market actors are today translating Coase's market theory into mainstream financial practice (Knox-Hayes, 2009). Guided by a range of "technologies of performance" such as standards, certification schemes and auditing practices, market actors are today able to commensurate diverse and disparate emission reduction activities around the world (e.g. energy efficiency measures, methane recovery projects, tree plantations) and make them appear "the same" on the carbon accountant's balance sheet (McKenzie, 2009). As a result the abstract and intangible "tCO2e" is today traded as any other commodity. In the following section we examine these calculative practices in further detail. We do so by tracing two carbon offsets and one carbon allowance bought by the authors of this paper to compensate for our air travels in 2007 and 2011. By examining the "technologies of performance" that have produced our CERs, VERs and EUAs as thinkable and comparable commodities, we seek to illustrate how the carbon economy is made up as a thinkable and coherent administrative domain.

\section{The making of a $C E R^{2}$}

In December 2007, one of the authors of this chapter purchased a "climate neutralization certificate" from the Swedish carbon broker Tricorona at a total cost of 288 USD. The offset was bought to neutralize a research trip to the $13^{\text {th }}$ Conference of the Parties to the UNFCCC in Bali, Indonesia. According to the certificate, the 6.15 tonnes of carbon dioxide generated by the return trip from Copenhagen to Denpasar were neutralised through the Sri Balaji biomass power plant in Andhra Pradesh, India. The plant's mitigation activities are registered under the CDM of the Kyoto Protocol, and therefore produce CERs that, in this case, were brokered by Tricorona.

According to decision 3/CMP.1 in the Marrakesh Accords, ${ }^{3}$ a Certified Emission Reduction is a unit that equals one metric tonne of carbon dioxide equivalents, calculated using the global warming potential developed by the IPCC and defined in article 5 of the Kyoto Protocol. The CER travels a long way, and is moulded by many actors and practices before it reaches the web store of carbon brokers such as Tricorona. It is

\footnotetext{
${ }^{2}$ An earlier version of this section was published in Stripple and Lövbrand (2010).

3 See 'CDM rules' in FCCC/KP/CMP/2005/8/Add.1, 30 March 2006.
} 
produced by project developers in a developing country, often in collaboration with Northern investors, approved and authorized by a designated national authority (DNA) in the host country, validated, verified and certified by a third party auditing firm, and finally, given a legal status by the CDM Executive Board (EB) - a supervisory body incepted at the UN climate conference in Marrakesh in 2001. This market arrangement is the result of a last minute compromise in Kyoto in 1997 between the full blown trading scheme suggested by US negotiators, and the Clean Development Fund proposed by Brazil. By simultaneously promoting cost-effective and flexible emission cuts and sustainable finance, the CDM was designed to reconcile the conflicting expectations and agendas of developed and developing states, the EU and the USA (Lövbrand et al., 2009). Since then an institutional framework has been developed to regulate the making and trade of CERs according to an eight-step project cycle (for an overview, see Bumpus, 2011).

The making of the CERs sold in Tricorona's web store in December 2007 began in February 2003 when the private power company Indur Green Power Private Ltd decided to displace fossil fuel based electricity in the Andra Pradesh state grid with electricity generated from renewable biomass. To fund the power plant and its condensing type steam generator, the company submitted a Project Design Document (PDD) to the national CDM authority in India for approval, and to the auditing firm Det Norske Veritas (DNV) for validation. According to the PDD, the biomass used in the plant is $\mathrm{CO}_{2}$ neutral. ${ }^{4}$ Hence, over a period of 7 years the operation will replace around 296 million kWh of conventional energy and avoid 245813 tonnes of carbon dioxide emissions. This claim was justified by a simplified baseline methodology for smallscale CDM projects accepted by the CDM EB's methodology panel in $2005 .^{5}$ By referring to financial and policy barriers for investments in biomass energy production (e.g. fuel availability, fluctuating prices and tariffs), these calculative practices have sought to establish the estimated emission reductions as real, measurable and additional to any that would occur in the absence of the project activity, hereby satisfying

\footnotetext{
4 Available for download at the UNFCCC webpage: http://cdm.unfccc.int/Projects/DB/DNVCUK1144412972.08.

${ }^{5}$ See 'Indicative simplified baseline and monitoring methodologies for selected small-scale CDM project activity categories'. Available for download: http://cdm.unfccc.int/Projects/pac/ssclistmeth.pdf.
} 
the eligibility criteria for CDM projects specified in article 12 of the Kyoto Protocol. ${ }^{6}$ According to Bumpus (2011), this process of categorising and separating out carbon from its local context is central in the making of a CER. Spatial abstraction allows the carbon to flow from the place of emission reductions (i.e. Andrah Pradesh, India) to the place of carbon emissions (i.e. Sweden) (Bumpus, 2011:10).

In September 2005, the Indian Ministry of Forestry and Environment officially approved the 7,5 MW Biomass Power Project of Indur Green Power Pvt Ltd as an activity that would contribute to sustainable development in the Andrah Pradesh region. ${ }^{7}$ One month after this third step in the CDM project cycle, DNV submitted its validation report to the CDM EB (DNV 2005). By measuring the project documentation against the multilateral criteria for CDM projects in the Kyoto Protocol and the Marrakesh accords, the DNV validation team established the estimated CERs as measurable (i.e. thinkable) and additional (i.e. legitimate). In line with Power (2003: 385) we approach these auditing procedures as ritualistic practices that bring order to a previously unordered world. When filtering the emission reduction activities of the Indian power plant through the lens of standardized techniques, auditing firms such as the DNV make it possible to think of organizationally discrete and spatially disparate carbon practices as comparable; i.e. the same. It is this ability to make the incommensurable seem commensurable (Larner and Heron, 2004: 214) that allows a CER to be represented as a standardized commodity with the same atmospheric effect regardless of its origin.

Two months after the official registration of Sri Balaji in May 2006, the Indur Green Power Private Ltd submitted a monitoring report to the CDM EB. According to the report the power plant had avoided 103763 tCO2eqv between February 2003 and March 2006 (Indur Green Power Pvt Ltd., 2006). The accuracy of this claim was later

\footnotetext{
${ }^{6}$ Kyoto Protocol to the United Nations Framework Convention on Climate Change.

11, 1997, 37 I.L.M. 32, available at http://unfccc.int/resource/docs/convkp/kpeng.pdf.

${ }^{7}$ The signed host country approval of the '7,5 MW Biomass Power Project of Indur Green Power Pvt Ltd' is available for download on the UNFCCC webpage: http://cdm.unfccc.int/Projects/DB/DNVCUK1144412972.08.
} 
verified by DNV after a desk-review of the data in the monitoring report and two onsite inspections in September 2006 (DNV, 2006). On the basis of the DNV's verification/certification report, the CDM EB decided to issue 81295 CERs in May 2007. ${ }^{8}$ In December the same year, six of these carbon offsets were sold to one of the authors of this paper via the Tricorona webpage. At this point in time the CDM market was at its peak. In 2007 almost 6 billion CERs were traded at a price of approximately 13 USD each (Kossoy and Ambrosi, 2010). Three years later the investment appetite in the CDM had waned and the trade in CERs reached a record low total value of approximately 1,5 billion USD (Linacre et al., 2011: 48). Hence, primary CERs, which used to account for a large portion of the global carbon market, only accounted for one percent of the total trade in year 2010 (ibid).

Market actors have for some time talked about the overly bureaucratic CDM project cycle as a reason for the decreasing trade (Kulovesi, 2007; Streck and Chiagas 2007). In 2010 the World Bank estimated that it takes over three years for the average CDM project to make its way through the regulatory process and issue its first CER (Kossoy and Ambrosi, 2010, section 1). The registration process by the CDM EB is often highlighted as a bottleneck (Streck and Lin, 2008). While some of these issues were resolved by the introduction of standardised baseline and monitoring methodologies at COP 16 in Cancun in 2010, these changes have not offered the regulatory predictability that the market is seeking in the post-2012 era (Linacre et al., 2011). The lack of clear political signals about the future of the Kyoto Protocol during and after COP 15 in Copenhagen in December 2009, has made many market actors look elsewhere for long-term carbon investments (Derwent, 2010: iv). Interestingly though, market actors do not seem to interpret the recent decline in the CDM market as a challenge to the carbon economy as such (Linacre et al, 2011). Although market actors may be concerned that a post-2012 agreement will be delayed, creating a gap between the time Kyoto expires and the implementation of a new agreement with fully functioning trading mechanisms, the neoliberal imagination of the market as a site for creative, flexible and responsible solutions seems to prevail. The CER may be replaced by another

\footnotetext{
${ }^{8}$ See the following webpage for full project documentation: http://cdm.unfccc.int/Projects/DB/DNVCUK1144412972.08.
} 
currency, but the saliency of the "tCO2e" remains firmly grounded in our imagination.

\section{The making of a $V E R^{9}$}

While 2010 was a challenging year for the CDM market, it was a record year for voluntary carbon offsetting. The global financial crisis that dampened demand for voluntary offsets in 2009 gave way for market growth as market actors sought credits from projects that reduce emissions from deforestation and forest degradation (REDD). Hence, the market share of the voluntary carbon market increased by 500 percent in one year to, a still small, 0.3 percent of the global carbon market (Linacre et al., 2011: 54). This voluntary market domain is often represented as a less regulated network of people and technologies than the CDM market (Lovell and Liverman, 2010). The various actors involved in the making of a VER are not necessarily accredited, a project is not necessarily validated, emission reductions are not necessarily verified and there are many different standards of verification working alongside each other. In the final stage of the global supply chain, the emission reductions are not necessarily certified and kept in a registry to prevent them from being sold twice. This lack of standardization suggests that the VER is more heterogeneous in character, and often seen as incommensurable with the CER. However, through the introduction of voluntary offset standards, the making of a VER has in many respects replicated the calculative practices that underpin the CER (for an overview, see Lovell 2010).

For the sake of illustration, we will here briefly outline three different types of voluntary offsets that one author of this chapter considered when offsetting a conference trip from Copenhagen to San Francisco in March 2008. The first offset was for sale on Ebay in late February 2008. The auction started at 0.99 USD, although the total amount of avoided emissions was somewhat unclear. According to the eBay seller, the offset was generated by himself. "I work at home and drive very little. I walk a lot and have a car that gets 36 mpg. I haven't travelled by air for at least 10 months. If

\footnotetext{
${ }^{9}$ An earlier version of this section was published in Stripple and Lövbrand (2009).
} 
you are commuting a lot and flying around the country you may need my offset." Whether this was a sincere attempt to sell emission reductions or not, the example is principally interesting since it departs from the requirement of additionality, central to the production of a CER under the Kyoto Protocol. As suggested by the quote, the seller's emission reductions are not calculated vis-à-vis a business-as-usual baseline, but in relation to a generalized idea of an equal share of emissions. Although this way of thinking about climate governance is far from new (see for instance Agarwal and Narain, 2001), it has not yet become an operational part of carbon market dynamics.

The second offset under consideration by the author was also sold on Ebay (but in a specific store) by the International Small Group and Tree Planting Program (TIST). TIST is a community-based organization that helps subsistence farmers in Tanzania, Kenya, Uganda and India to produce commercial carbon offsets through tree plantation programmes and modern satellite technology, such as GPS. The farmers use the satellite monitoring system to measure and report the amount of atmospheric carbon sequestered by their trees, and to upload the coordinates and measurements of the trees to the TIST webpage for increased transparency. According to Hawn (2006), the supply of this virtual cash crop has certain advantages: "TIST farmers have found that modern technology lets them leapfrog some of the hurdles that in the past had plagued their access to markets. They no longer need to transport products like mangos or tea across long distances on unpaved roads; they simply transmit information across oceans" (Hawn, 2006: 2). By 2006, TIST had sold some 180 VERs via its Ebay store and another 5000 directly to customers, including the World Bank (Hawn, 2006). However, none of these offsets were calculated in a manner that satisfied the eligibility criteria under the Kyoto Protocol's baseline and credit regulations.

The third type of voluntary offset, the one finally chosen by the author, was, however, made up by similar calculative practices as those underpinning the compliance market. The 2.53 " $\mathrm{tCO} 2 \mathrm{e}$ " generated by the author's return trip from Copenhagen to San

\footnotetext{
${ }^{10}$ The carbon offset was found on Ebay on February 02, 2008 as item number 250218013349. The page is now removed, but a copy of the webpage from that day can be found here: http://www.svet.lu.se/documents/JST_Carbonoffsets.pdf
} 
Francisco were offset by the UK-based firm Climate Care at a total cost of 38 USD. The offset contract, purchased via the broker's web store, does not specify where or how the VERs were produced. Instead, the return flight was compensated for by a portfolio of projects located in different parts of the world. Since Climate Care employs a number of voluntary offset standards for their projects, it is nonetheless possible to reconstruct the making of the VERs purchased by the author. As outlined by the official manuals and guidelines for the Voluntary Carbon Standard (VCS) and the VER+, offset projects following these standards are adjusted to a number of baseline and monitoring methodologies developed to ensure project additionality. In order to avoid double accounting, both standards also coordinate a registry that accounts for the issued, held and retired VERs. ${ }^{11}$ While these standardized carbon accounting procedures are designed to secure the commensurability of the resulting VERs, the Gold Standard VER (GS VER) is, instead, a standard that seeks to differentiate VERs. Using a set of criteria, for example, a positive list of project types, sustainable development, and civic involvement, the Gold Standard seeks to produce high quality VERs that appeal to carbon consumers who seek to do good. ${ }^{12}$

Although these standards govern the voluntary market according to different logics, (making things the same vs. making things different), they have, interestingly, made the supply chain of the VER very similar to that of the CER. The baseline-and-credit methodologies used to secure additionality by VCS and VER+, or the sustainability indicators developed by the Gold Standard, all draw upon the multilateral rules developed for the CDM. Hence, when analyzing carbon markets through the practices that constitute or perform them, they can no longer be divided into one regulated $p u b$ lic zone and one unregulated private zone as often implicated in writings on the carbon economy (Lovell and Liverman, 2010). Rules for governing carbon markets are evolving with the markets, and accounting practices specified for the Kyoto Protocol are now copied and transformed beyond their initial reach. Hence, the search for common standards, registries and accounting procedures for the "tCO2e" questions the relevance of the public-private distinction in carbon market governance.

\footnotetext{
11 Read more about the VCS at http://www.v-c-s.org/about.html, and VER+ at http://www.tuevsued.de/uploads/images/1179142340972697520616/Standard_VER_e.pdf.

${ }^{12}$ Read more about the Gold Standard at: http://www.cdmgoldstandard.org.
} 


\section{The making of an EUA}

In principle, consumers or firms can today offset their emissions by any type of carbon unit. In practice, however, offsetting has come to be associated with the project based carbon markets outlined above. This is the type of carbon trade that has been subject to most critique (Lohmann, 2006; Böhm and Dabhi, 2009). Project based offsetting render carbon emissions visible through their marketisation - turning them into standardised commodities, abstracted from their local context and metabolised into exchangeable values across space (Bumpus, 2011: 2). However, there are some exceptions to these project-based offsetting practices. In 2005 the Swedish Society for Nature Conservation (the largest Swedish environmental NGO) recommended individuals, corporations and public agencies to "climate compensate" by purchasing emission allowances within the EU ETS. Similarly, a UK-based NGO, Sandbag, urged individuals to engage in "carbon destruction" by purchasing European Union Allowances (EUA) and retiring them. Sandbag supports the European Union's legal cap on carbon emissions, but claims that the incentive to reduce emissions within the EU ETS is too low. Too many permits have been issued to Europe's big polluters. Hence, "Sandbag's Carbon Destruction lets you take action to change this: Buy permits and immediately take them out of the system. Fewer permits mean less pollution." 13

The EU ETS is the world's largest emission trading system and is at the heart of EU climate policy. According to van Asselt (2010: 1), the inception of the EU ETS in 2005 represents an "enthusiastic adoption of an alien instrument". At that point in time, only few countries had experimented with emission trading, and no trading scheme had been implemented at a supranational level. The EU ETS was the first out of the cap-and-trade systems presented in Table 1, and the EUA quickly became the most traded carbon unit. New schemes are now emerging in the US, New Zealand, Japan and Norway, although the very quick proliferation of carbon markets seems to have come to a halt after the Copenhagen meeting in 2009 (Linacre et al., 2011). The

\footnotetext{
${ }^{13}$ See their website at http://www.sandbag.org.uk, accessed on April 26, 2011.
} 
EU ETS is a cap-and-trade based system, which fixes the number of emission allowances within the EU and distributes them to the Member States. The system currently covers over 10000 energy intensive industries across the EU-25 (accounting for almost half of the EU's carbon emissions). The precise method for allocating allowances to these industries has been revised over the years. In the first two phases (20052012), free allocation based on historical emissions ("grandfathering") became the standard approach. In the third phase (2013-2020), however, the design of the EU ETS is changing considerably. The overall emission "cap" will not be determined by the Member States, but instead by the European Commission. Furthermore, the Commission will sell emission allowances to polluting firms. Such "auctioning" will start with the power sector. Full auctioning across the board is expected by 2027.

Although the EUA is firmly established as the basic unit of exchange in the EU ETS, it is not exactly clear what kind of unit it is. The EC Council Directive establishing the EU ETS defines the EUA as "an allowance to emit one tonne of carbon dioxide equivalent during a specified period, which shall be valid only for the purposes of meeting the requirements of this Directive and shall be transferable in accordance with the provisions of this Directive" (2003/87/EC) ${ }^{14}$ Hence, in contrast to the Marrakesh Accords' definition of a CER, the EUA is defined not in terms of what the unit is, but what it entitles the holder to do. According to Button (2010), this kind of definition is typical for contemporary practices of carbon commodification. "Even though that the prevailing tendency is to treat carbon as a commodity, a carbon unit is a sui generis right which can be traded like a currency" (Button 2010: 595). MacKenzie (2009) displays how the International Financial Reporting Interpretations Committee (IFRIC), a subsidiary body to the International Accounting Standards Board, has wrestled with applying accounting standards to allowances. What kind of items are they? Are they indeed "rights", "intangible assets" or "financial instruments"?

\footnotetext{
${ }^{14}$ The directive 2003/87/EC is to be found in the Official Journal of the European Union L 277532 and availible for download at http://eurlex.europa.eu/LexUriServ/LexUriServ.do?uri=OJ:L:2003:275:0032:0046:en:PDF
} 
This question gained salience in December 2009 when Europol estimated that the EU ETS had generated a tax fraud resulting in a 5 billion EUR loss in tax revenue for several member states (Kossoy and Ambrosi, 2010). Since EUAs traded on a spot basis are treated as actual goods, carbon transactions across EU boarders are subject to Value Added Tax (VAT). Secondary carbon products traded as futures and options, however, are considered financial transactions and are therefore exempted from VAT within the EU. In 2009 Europol found that many carbon transactions had passed undeclared to the relevant governments. Although this VAT fraud debacle led to criminal charges in France, Spain and the UK, it interestingly emphasised the importance of the EU ETS and the saliency of the EUA as carbon currency. As noted by Kossoy and Ambrosi (2010, section 2), “(e)ntities don't seek out loopholes in insignificant markets, fraudsters do not focus on small business".

Consequently, when offsetting a conference trip to Geneva in March 2011, one of the authors of this paper decided to buy one EUA to a price of 25 EUR. The transaction was brokered by the Swedish Society for Nature Conservation (SNF) and conducted via their webpage. ${ }^{15}$ In order to estimate the amount of carbon generated by the return trip Copenhagen-Geneva, a carbon calculator provided by Atmosfair (a German carbon broker) was used. ${ }^{16}$ The calculation resulted in a "climate impact" of about 540 $\mathrm{kg}$ of $\mathrm{CO}_{2}$. According to Atmosfair this "carbon footprint" can be compared to the use of a refrigerator one year $\left(100 \mathrm{~kg} \mathrm{CO}_{2}\right)$, the total emissions of one Indian citizen $(900$ $\mathrm{kg} \mathrm{CO}$ ) or one year of car driving (12000 km, middle class model). Atmosfair offered to offset the $540 \mathrm{~kg}$ for 13 EUR. However, returning to the webpage of Swedish Society for Nature Conservation (SNF), one EUA was instead bought to a price of 250 SEK (around 25 EUR). According to the certificate provided by SNF, this purchase represents the right to pollute one "tCO2e" within EUs "emission bubble" during the period 2008-2012. However, the SNF also informs the buyer that he or she can refrain from using the right and hereby contribute to greenhouse gas reductions. By withholding an emission right from the system, the SNF asks its consumers to reduce the "emission space" for the big polluters in the EU.

\footnotetext{
${ }^{15} \mathrm{http}: / /$ www.naturskyddsforeningen.se/stod-oss/privat/utslappsratter/

${ }^{16} \mathrm{http}: / /$ www.atmosfair.de/en/
} 
Hence, in comparison to how offsetting works in the project-based carbon markets, the EUA is not tied to any particular industry installation. The making of an EUA does not start off by separating it from a local context as in the case of the CER or the VER (cf. Bumpus, 2011). Although registered in national transaction logs and subject to national VAT laws, this most traded carbon currency to date is from its inception "spatially abstract".

\section{Carbon market governance post Copenhagen}

Ten years after the invention of the "tCO2e" as the basic unit of account in the Marrakesh Accords, carbon market governance has become normalised mitigation practice. Through standardised carbon monitoring, verification and certification procedures, developed within the regulated Kyoto and EU ETS markets in 2005, and later adopted by voluntary and regional markets across the globe, emission reduction activities are today abstracted from their local context and transformed into a standard unit of account that can be traded across time and space. As MacKenzie (2009) has pointed out, the contemporary trade in carbon offsets hinges on making diverse and disparate activities part of the same balance sheet. As illustrated by our three examples above, numbers transform qualitative distinctions into quantitative differences and allow seemingly incommensurable practices - such as travelling by air from Sweden to Indonesia, managing a forest in Tanzania or running a power plant in Europe - to appear the same in the carbon accountant's book. The every-day practices of financial intermediaries such as carbon exchanges, banks and brokerages have, in turn, modelled this trade on the financial market and hereby produced a range of primary and secondary carbon products bought and sold at different prices.

As we move into 2012 and the end of the Kyoto Protocol's first commitment period, we may expect an increased differentiation between market segments and carbon products. Firstly, the outcomes from the COP 16 to the UNFCCC in Cancun in December 2010 suggest that we may see the introduction of new carbon products and currencies linked to policy instruments such as Nationally Appropriate Mitigation Actions (NAMAs) for developing countries and Reducing Emissions from Deforestation and Forest Degradation (REDD). Although the design of these instruments are far 
from settled and are closely linked to the cumbersome UN negotiations on a post2012 agreement, market actors hope that they will generate new kinds of credits and hereby mobilise financial flows in a similar way as did the CDM after the entry into force of the Kyoto Protocol (Linacre et al., 2011). Secondly, in the absence of a UN coordinated post-2012 agreement, we may expect a more fragmented and complex market landscape in the years to come. While some market actors worry that the absence of a multilateral framework that regulates market demand and establishes common accounting and monitoring standards will make efforts to link regional trading schemes and offsetting practices increasingly complex, others welcome the benefits of regional market systems with high adaptability and fast approval processes (Linacre et al., 2011: 37). Thirdly, differentiation will most likely also continue to function as a "technologies of agency" that seek to mobilise responsible carbon consumers to take stand in the carbon market place and make informed consumer choices according to the risks and sustainability performance of different offsetting practices. Suggestions to introduce differentiated levies on CDM projects, or voluntary performance standards such as the Gold Standard represent important contemporary examples of efforts to differentiate carbon units according to their "moral qualities".

In sum, we suggest that this tension between practices of commensuration and differentiation is likely to characterize carbon market dynamics in the post-Copenhagen era. Future efforts to govern the carbon economy will thus balance between "technologies of performance" (e.g. monitoring, validation, verification, certification) that seek to stabilize the "tCO2e" as a generic public good, and "technologies of agency" that shed light on the different locations and socio-economic circumstances under which efforts to reduce greenhouse gas emissions take place. Interestingly though, there is little evidence that the past two years of market turmoil, with reduced demand for carbon assets, tax-fraud charges and focus on the speculative nature of carbon derivatives ('subprime carbon', see FOE 2009), has challenged the "tCO2e" as commodity. Rather, Kossoy and Ambrosi (2010, section 2) interpret the EU ETS VAT scandal as a sign of market maturity and the gradual mainstreaming of carbon trading within the European economy. In a similar vein, Paterson (2009) notes that the civic critique against scams in the CDM and voluntary offset markets (see Böhm and Dabhi, 2009) has been important in shaping the very character of those markets in the first place. 
The operational rules, informal norms and changing dynamics are produced, at least in part, by the reaction to opposition to carbon markets (Paterson, 2009: 250).

Paterson and Stripple (2011, forthcoming) describe the carbon offset as a "virtuous commodity". The term captures the close affinity between virtuality and virtue — the technological and the moral - in its construction. Conceiving of carbon credits as virtuous commodities thus captures both the imagination of a set of practices that can be brought into being (virtuality), and the ascription of a normative value to those imagined practices (virtue, what we can do, we should). In line with a neoliberal governmentality, this morality of carbon markets is conceived of in terms of a preferential freedom-of-choice model that rejects morally prescriptive regulation from above (Shamir, 2008: 12). Instead carbon market performance is governed "at a distance" through a range of "moral instruments" such as certification standards, rating devices and benchmarks among which market actors may pick and choose. This moralisation of carbon markets neatly fits the neo-liberal principle of private self-regulation, and, in the words of Shamir (2008:13); "successfully grounds the very notion of moral duty within the rationality of the market: doing good is good for business." Hence, by imbuing the commodities of carbon markets with a self-evident moral quality resistance is neutralised and turned into practices that "make carbon markets" (Paterson, 2009).

\section{Conclusions}

In this paper we have drawn upon Foucauldian governmentality studies to examine the constituting ways of thinking and acting that make up the carbon economy and render it practicable and amendable to intervention. In contrast to the governance literature's efforts to conceptualise the carbon economy according to the actors and sources of authority involved, we have turned attention to the practices and ways of thinking that inform carbon market governance and hereby render the carbon economy governable. Our study suggests that the every-day making of tradable offset credits and carbon allowances indeed involves a whole range of private market actors (e.g. auditing firms, legal advisors, consultancy firms, banks, scientific experts) who warrant further scrutiny. However, when excavating two carbon offsets and one carbon allowance from the very practices that perform them, our attention has been drawn 
away from these actors and instead turned to the practical skills and materialities that have turned carbon emissions (avoided, sequestered or reduced) into a commodity like any other.

By locating our study of the carbon economy in the post-Copenhagen era, we expected to see contestation and a rethinking of how the private realm is mobilised for the purpose of climate change mitigation. While our study indeed identified a great portion of market turmoil linked to the regulatory uncertainty produced by the COP 15 outcome in Copenhagen in December 2009 and the EU ETS VAT scandal, we did not find evidence that the saliency of the "tCO2e" as commodity is challenged, nor that the imagining of the market as an active and responsible partner in the governance of climate change has eroded. In a time when governments are struggling to agree upon a successor agreement to the Kyoto Protocol, the neo-liberal rationality of the carbon economy seems more ingrained in our imagination than ever. Informed by ideas advanced in climate science and resource economics, responsible climate action now rests upon the willingness of private consumers and carbon market actors to "do good" through the carbon market place. Through a few "clicks" on the web pages of carbon brokers such as Tricorona, Climate Care or the Swedish Society for Nature Protection, knowledgeable consumers and purchasing firms are today asked to calculate their "carbon footprints" and "neutralise" their climate impacts through the purchase of a selected number of "tCO2e". In this paper we have not primarily analysed how these "technologies of agency" work upon subjects, selves and agents. Instead we have examined the many "technologies of performance" that currently regulate carbon market performance at a distance.

When focusing on these "calculative practices", carbon market governance does not signify a retreat of the state or politics as often implied by scholars of global governance. Rather, we argue that the carbon economy as imaginary space represents a transformation of politics and statehood that involves a replacement of formal and hierarchical techniques of government with more indirect regimes of calculation. The involvement of private actors in carbon market governance is, from this vantage point, not interpreted as an instance of transferring power from the state to non-state actors. It is rather an expression of a changing rationality of government where the private 
realm becomes elevated from being a passive terrain to be acted upon and turned into an entity that is both object and subject of government. Although the carbon economy may be surrounded by less energy and passion in the post-Copenhagen era, we expect carbon market rationalities to inform climate governance also in the years to come.

\section{References}

Agarwal A, Narain S, 1991 Global Warming in an Unequal World: a Case of Environmental Colonialism. (Centre for Science and Environment, New Delhi)

Andonova L, Betsill MM, Bulkeley H, 2009, "Transnational climate governance" Global Environmental Politics 9(2) 52-73

Asselt $\mathrm{H}$ van, 2010, "Emissions trading: the enthusiastic adoption of an alien instrument?", in Climate Change Policy in the European Union: Confronting the Dilemmas of Mitigation and Adaptation? Eds A Jordan, D Huitema, H van Asselt, T Rayner, F Berkhout (Cambridge University Press, Cambridge) pp 125-144

Bäckstrand K, 2008, "Accountability of networked climate governance: the rise of transnational climate partnerships" Global Environmental Politics 8 (3)74-104

Barry A, Osborne T, Rose N, Eds 1996 Foucault and Political Reason: Liberalism, Neo-liberalism and Rationalities of Government (UCL Press, London)

Bernstein S, Betsill M, Hoffman M, Paterson M, 2010, “A tale of two Copenhagens: carbon markets and climate governance" Millennium 39(1) 161-173

Biermann F, Gupta A, 2011, "Accountability and legitimacy in earth system governance: A research framework" Ecological Economics 70(11) 1856-64

Biermann F, Pattberg P,Asselt H v, Zelli F, 2009, “The Fragmentation of global governance architectures: A framework for analysis" Global Environmental Politics 9(4) 14-40

Böhm S, Dabhi S, Eds 2009 Upsetting the Offset: the Political Economy of Carbon Markets (Mayfly Books, Colchester)

Bumpus AG, 2011, "The matter of carbon: understanding the materiality of tCO2e in carbon offsets" Antipode 43(3) 612-638 
Button J, 2008, "Carbon: commodity or currency? The case for an international carbon market based on the currency model" Harvard Environmental Law Review 32 571-596

Callon M, 1998 The Laws of the Markets (Blackwell Publishers/Sociological Review, Oxford; Malden, MA)

Callon M, Millo Y, Muniesa F, 2007 Market Devices (Blackwell Publishers, Malden, MA)

Callon M, 2009, "Civilizing markets: Carbon trading between in vitro and in vivo experiments" Accounting, Organizations and Society 34 535-548

Coase R, 1960, "The problem of social cost" Journal of Law and Economics 3 1-44

Cutler AC, Haufler V, Porter T, Eds 1999 Private Authority and International Affairs. (State University of New York Press, Albany)

Dales JH, 1968 Pollution, Property and Prices (University of Toronto Press, Toronto, Canada)

Dean M, 2004 Governmentality: Power and Rule in Modern Society (Sage Publications, London; Thousand Oaks, California)

Derwent H, 2010, "Message from the president" in Greenhouse Gas Market 2010. Post-Copenhagen and Climate Policy: Where Global Emissions Trading goes from Here Eds A Kramer (International Emissions Trading Association, Geneva)

Descheneau P, Paterson, M., 2011, "Between desire and routine: assembling environment and finance in carbon markets" Antipode 43(3) 662-681

Det Norske Veritas (DNV) 2005 Validation Report. Indur 7,5 Non-Conventional Renewable Sources Biomass Power Project in India, Report No. 2005-9008. Online access at: http://cdm.unfccc.int/Projects/DB/DNV-CUK1144412972.08

Det Norske Veritas (DNV) 2006 Verification/Certification Report. Indur 7,5 NonConventional Renewable Sources Biomass Power Project in India, Report No. 2006-9116. Online access at: http://cdm.unfccc.int/Projects/DB/DNVCUK1144412972.08.

Eliasch J, 2008 Climate Change: Financing Global Forests (Office of the Prime Minister, London) 
FCCC/KP/CMP/2005/8/Add.2, page 18 [online], UNFCCC. Online access at: http://unfccc.int/resource/docs/cop7/13a02.pdf

Friends of the Earth [FOE] 2009 Subprime Carbon? Re-thinking the World's Largest New Derivatives Market (Friends of the Earth, Washington DC)

Hall RB, Biersteker T, Eds 2002 The Emergence of Private Authority in International Affairs (Cambridge University Press, Cambridge)

Hawn A. 2006, "Carbon credits on eBay: Subsistence farmers sell ecosystem services in a virtual marketplace" Conservation Magazine 7: 4

Hoffmann MJ, 2011 Climate Governance at the Crossroads: Experimenting with a Global Response after Kyoto (Oxford University Press, Oxford).

Indur Green Power Private Ltd 2006 Monitoring Report Indur 7,5 Non-Conventional Renewable Sources Biomass Power Project in India, Reference No. UNFCCC 0391, Online access at: http://cdm.unfccc.int/Projects/DB/DNVCUK1144412972.08

Knox-Hayes J, 2009, "The developing carbon financial services industry: expertise, adaptation and complementarity in London and New York" Journal of Economic Geography 9 749-777

Kossoy A, Ambrosi P, 2010 State and Trends of the Carbon Market 2010 (World Bank, Washington DC)

Larner W, Heron RL, 2004, “Globalizing benchmarking: participating 'at a distance' in the globalizing economy", in Global governmentality: governing international spaces Eds W Larner, W Walters (Routledge, New York, NY) pp $212-232$

Linacre N, Kossoy A, Ambrosi P, 2011 State and Trends of the Carbon Market 2011 (World Bank, Washington DC)

Lohmann L, 2006, "Carbon Trading. A critical conversation on climatechange, privatisation and power" Development dialogue no. 48

Lövbrand E, Nordqvist J, Rindefjäll, T, 2009,“Closing the legitimacy gap in global environmental governance: Examples from the emerging CDM market" Global Environmental Politics 9(2) 74-100

Lovell H, Bulkeley H, Liverman D, 2009, "Carbon offsetting: sustaining consumption?" Environment and Planning A 41 2357-2379 
Lovell H, 2010,"Governing the carbon offset market" Wiley Interdisciplinary Reviews: Climate Change 1(3) 353-62

Lovell H, Liverman D, 2010, "Understanding carbon offset technologies" New Political Economy 15(2) 255-273.

MacKenzie D, 2009, "Making things the same: Gases, emission rights and the politics of carbon markets"Accounting, Organizations and Society 34(3-4) 440-55

MacKenzie D, Millo Y, 2003, "Constructing a market, performing theory: The historical sociology of a financial derivatives exchange" American Journal of Sociology 109 107-145

Miller P, Rose N, 2008 Governing the Present (Policy Press, Cambridge)

Muniesa F, Millo Y, Callon M, 2007 “Introduction to market devices", in Market Devices Eds Callon M, Millo Y, Muniesa F (Blackwell Publishers, Malden, MA) pp 1-12

Newell P, Paterson M, 2010 Climate Capitalism. Global Warming and the Transformation of the Global Economy (Cambridge University Press, Cambridge)

Neumann IB, Sending OJ, 2010 Governing the Global Polity. Practice, Mentality, Rationality (The University of Michigan Press, Ann Arbor)

Oels A, 2005, "Rendering climate change governable: From biopower to advanced liberal government?" Journal of environmental policy and planning 7(3) 185207

Paterson M, 2009, "Resistance makes carbon markets" in Upsetting the Offset: the political economy of carbon markets Eds Böhm S, Dabhi S (Mayfly Books, Colchester)

Paterson M, Stripple J, 2010 "My Space: governing individuals' carbon emissions" Environment and Planning D: Society and Space, 28(2) 341-362

Paterson M, Stripple J, 2011 "Virtuous Carbon" Environmental Politics - Accepted and forthcoming in special issue on the politics of carbon market creation.

Paterson M, 2011, "Climate re-public: practicing public space in conditions of extreme complexity". Draft chapter for J Best and A Gheciu Eds The Public as Practice: Transformations in Global Politics (Cambridge University Press) 
Pattberg P, Stripple J, 2008, "Beyond the public private divide: remapping transnational climate governance in the 21 century" International Environmental Agreements. 8 367-388

Pigou AC, 1920 The Economics of Welfare, 1938, 4th edition (Macmillan, London)

Power MK, 2003, “Auditing and the production of legitimacy” Accounting, Organizations and Society 28(4) 379-379

Prins G, Rayner S, 2007, "Time to ditch Kyoto” Nature 449(7165) 973-75.

Rose N, 1996, "Governing 'advanced' liberal democracies", in Foucault and Political Reason: Liberalism, Neo-liberalism and Rationalities of Government Eds A Barry, T Osborne, N Rose (UCL Press, London)

Rosenau J, Czempiel EO, 1992 Governance without Government. Order and Change in World Politics (Cambridge University Press, Cambridge)

Shamir R, 2008, "The age of responsibilization: on market-embedded morality" Economy and Society 37(1) 1-19

Stern NH, 2007 The Economics of Climate Change: the Stern Review (Cambridge University Press, Cambridge)

Strange S, 1996 The Retreat of the State. The Diffusion of Power in the World Economy (Cambridge University Press, Cambridge)

Streck C, Chagas TB, 2007, "The Future of the CDM in a post-Kyoto world" Carbon and Climate Law Review 1(1): 53-63.

Streck C, Lin J, 2008, "Making markets work: A review of CDM performance and the need for reform" European Journal of International Relations 19(2) 409-442

Stripple J, Lövbrand E, 2010, "Carbon market governance beyond the public-private divide" in Global Climate Governance Post 2012: Architectures, Agency and Adaptation Eds F Biermann, P Pattberg F Zelli (Cambridge University Press, Cambridge)

Stripple J, Pattberg P, 2010, “Agency in global climate governance: setting the stage"in Global Climate Governance Post 2012: Architectures, Agency and Adaptation Eds F Biermann, P Pattberg FZelli (Cambridge University Press, Cambridge)

Stripple J, Bulkeley H, Hildingsson R, Stephan H, Andersson R, Nielsen T, 2011 Governing the Global Climate Polity: Rationality, Practice and Power, Work- 
shop report, September 2011, Lund University. Online access at: http://www.svet.lu.se/documents/JST_WS_june2011.pdf

Victor D, House JC, 2004, “A new currency: climate change and carbon credits" Harvard International Review summer 56-59

Wara M, 2007, “Is the global carbon market working?” Nature 445: 595-596.

Weart SR, 2003 The Discovery of Global Warming (Harvard University Press, Cambridge, London) 